\title{
A carbon dioxide insufflation technique for preparation of the internal thoracic artery
}

\author{
Mehmet Özkan, MD, ${ }^{a}$ Alp Aslan, MD, ${ }^{a}$ Mehmet Oguz, MD, ${ }^{a}$ Celil Yildirim, MD, ${ }^{\text {a }}$
} Levent Oktar, MD, ${ }^{\mathrm{b}}$ Göksel Ergül, MD, ${ }^{\mathrm{b}}$ and Ümit Özyurda, MD, ${ }^{\mathrm{a}}$ Ankara, Turkey

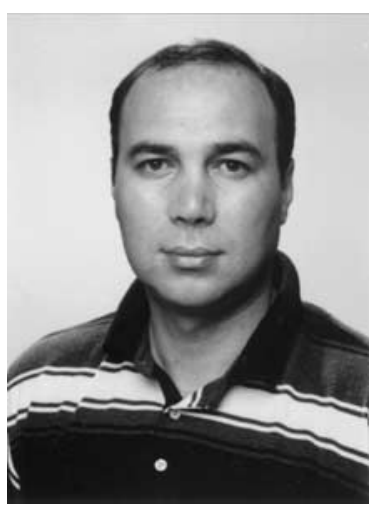

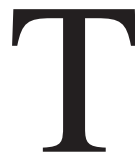
he internal thoracic artery (ITA) has become the conduit of choice for coronary artery bypass grafting because of its superior patency rates and longer survival when compared with that of saphenous vein grafts. ${ }^{1-4}$ The dissection technique of the ITA might affect the graft flow capacity. ${ }^{5}$ In addition to the well-known pedicle preparation technique of this arterial conduit, alternative techniques have been explored to minimize chest wall trauma, with reduced risk of sternal wound infection. We herein present a carbon dioxide insufflation technique of pedicle preparation of the ITA that appears to be safe, simple, and reliable.

\section{Technique}

After a median sternotomy, carbon dioxide is insufflated into the endothoracic fascia and the ITA by using an injector with a

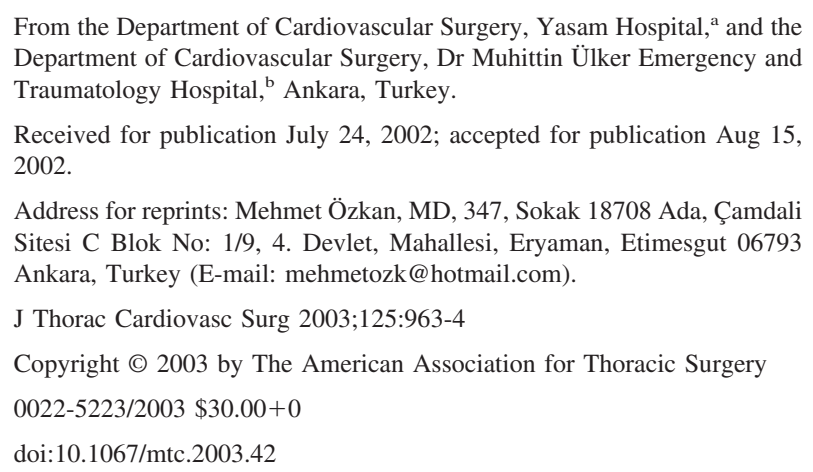

Received for publication July 24, 2002; accepted for publication Aug 15, 2002.

Address for reprints: Mehmet Özkan, MD, 347, Sokak 18708 Ada, Çamdali Sitesi C Blok No: 1/9, 4. Devlet, Mahallesi, Eryaman, Etimesgut 06793 Ankara, Turkey (E-mail: mehmetozk@hotmail.com).

J Thorac Cardiovasc Surg 2003;125:963-4

Copyright (C) 2003 by The American Association for Thoracic Surgery $0022-5223 / 2003 \$ 30.00+0$

doi: $10.1067 / \mathrm{mtc} .2003 .42$

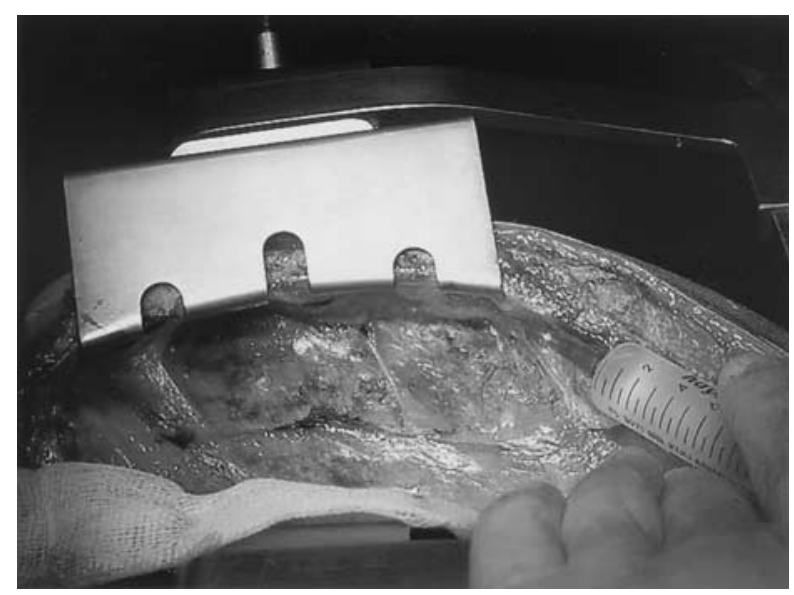

Figure 1. Carbon dioxide insufflation into the endothoracic fascia by using an injector with a 24-gauge needle. 24-gauge needle to form subpleural emphysema (Figures 1 and 2). This leads to easier dissection of the ITA with minimal use of electrocautery. The ITA is never touched directly with the forceps. Perforating vessels and intercostal artery branches are occluded with hemoclips on the ITA side, and electrocautery is used on the chest wall side of the vessels. The dissection is proximally carried to the superior border of the first rib and caudally beyond the bifurcation into the superior epigastric and musculophrenic arteries by using the standard pedicle preparation technique. We have used this technique in 28 consecutive patients, with no incidence of any complications.

\section{Comment}

The ITA can be used as a pedicled or skeletonized vessel conduit or a free graft. ${ }^{5}$ There is no doubt that the ITA graft prepared as a pedicle functions well in myocardial revascularization procedures. ${ }^{2,3}$ However, the hypoperfusion syndrome in coronary artery bypass grafting with the ITA is a well-known problem of a disproportion between ITA flow and myocardial demand and has a high mortality. ${ }^{6}$ In this situation flow can be limited as a result of a vasospasm or mechanical irritation of the arterial conduit. ${ }^{7}$ In our carbon dioxide insufflation technique, minimal use of electrocautery and a shorter dissection time and its vasodilator effect might

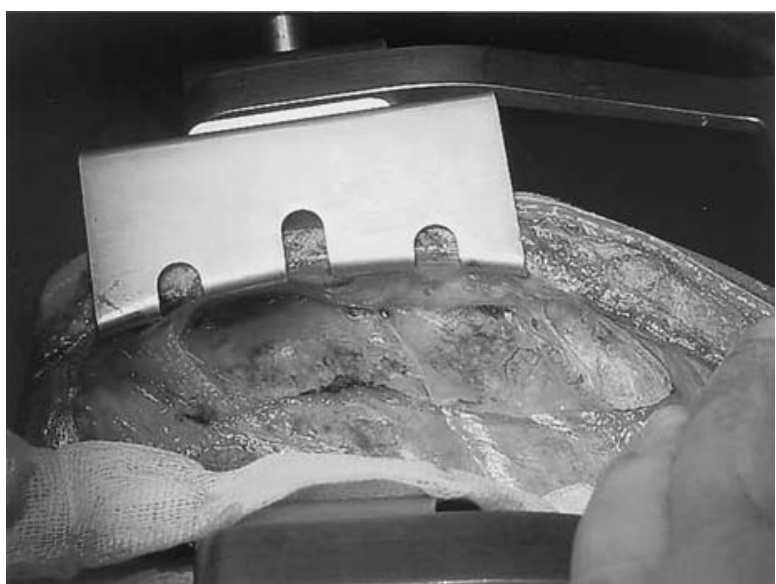

Figure 2. Subpleural emphysema along the ITA. 
reduce the risk of vasospasm of the ITA. This carbon dioxide insufflation technique for the pedicled ITA grafts is also sufficiently simple to adopt, even for inexperienced surgeons.

\section{References}

1. Sigh RN, Sosa JA, Green GE. Long-term fate of the internal mammary artery and saphenous vein grafts. J Thorac Cardiovasc Surg. 1983; 86:359-63.

2. Okies JE, Page US, Bigelow JC, Krause AH, Salomon NW. The left internal mammary artery: the graft of choice. Circulation. 1984; 70(suppl):I213-21.
3. Loop FD, Lytle BW, Cosgrove DM, et al. Influence of the internalmammary-artery graft on 10-year survival and other cardiac events. N Engl J Med. 1986;314:1-6.

4. Hilier C, Watt PA, Spyt TJ, Thurston H. Contraction and relaxation of human internal mammary artery intraluminal administration of papaverine. Ann Thorac Surg. 1992;53:1033-7.

5. Choi JB, Lee SY. Skeletonized and pedicled internal thoracic artery grafts: effect on free flow during bypass. Ann Thorac Surg. 1996;61: 909-13.

6. Jones EL, Lattouf AM, Weintraub WS. Catastrophic consequences of the internal mammary artery hypoperfusion. $J$ Thorac Cardiovasc Surg. 1989;98:902-7.

7. Wendler O, Tscholl D, Huang Q, Schäfers HJ. Free flow capacity of skeletonized versus pedicled internal thoracic artery grafts in coronary artery bypass grafts. Eur J Cardiothorac Surg. 1999;15:247-50.

\title{
Tricuspidalization of a bicuspid aortic valve with severe aortic valve insufficiency
}

\author{
Afksendiyos Kalangos, MD, PD, FETCS, ${ }^{a}$ Maurice Beghetti, MD, ${ }^{\text {b }}$ and Jan T. Christenson, MD, PhD, FETCS, \\ Geneva, Switzerland
}

\section{A} ortic valve insufficiency that develops in association with a ventricular septal defect (VSD) is usually caused by leaflet prolapse. In the event of severe aortic valve insufficiency, several techniques to repair the aortic leaflet prolapse have been described. ${ }^{1-5}$ An added problem occurs when the aortic valve is bicuspid. In this report we describe an original technique for transforming a bicuspid aortic valve into a tricuspid valve in a child.

\section{Clinical Summary}

The patient was a 14-year-old girl who, since 1996, had symptoms of a perimembranous VSD (with an extension just below the aortic annulus) combined with a bicuspid aortic valve and severe aortic valve insufficiency and an elongated and prolapsed posterior leaflet (Laubry-Pezzi congenital malformation). Because of rapid clinical deterioration with increasing dyspnea, she was referred to our center for corrective surgery in May 2002 from Morocco. Preoperative echocardiography revealed a high VSD with subaortic extension and a left-to-right ventricular pressure gradient of 42

From the Departments of Cardiovascular Surgery ${ }^{\mathrm{a}}$ and Pediatric Cardiology, ${ }^{\text {b }}$ University Hospital of Geneva, Geneva, Switzerland.

Received for publication July 26, 2002; accepted for publication Aug 20, 2002.

Address for reprints: Jan T. Christenson, MD, PhD, FETCS, Department of Cardiovascular Surgery, University Hospital of Geneva, 24 rue Michelidu-Crest, CH-1211 Geneva 24, Switzerland (E-mail: jan.christenson@hcuge.ch).

J Thorac Cardiovasc Surg 2003;125:964-6

Copyright $\odot 2003$ by The American Association for Thoracic Surgery $0022-5223 / 2003 \$ 30.00+0$

doi: $10.1067 / \mathrm{mtc} .2003 .155$ $\mathrm{mm} \mathrm{Hg}$, together with a severe aortic valve insufficiency and a dilated left ventricle.

\section{Surgical Technique}

The patient was operated on through a median sternotomy with cardiopulmonary bypass. After transverse opening of the ascending aorta and selective cardioplegia, the aortic valve was inspected. A bicuspid aortic valve with severe prolapse caused by elongation of the posterior leaflet was observed (Figure 1,A) together with a large VSD, which was easily accessible through the aortotomy and through the aortic valve. It was closed with a bovine pericardial patch through the same direct approach.

Thereafter, the false commissure of the anterior fused leaflet was incised, and reconstruction of a third commissure was started by suturing a semiellipsoid piece of bovine pericardium to the incised leaflet edges with a running suture (Figure 1, B). The ending of the patch at the free border of the leaflet was secured on both sides with an additional suture. The midportion of the ellipsoidal pericardial patch was then fixed to the aortic wall, thus transforming the false commissure into a true third commissure and the bicuspid valve into a tricuspid valve (ie, tricuspidalization; Figure 1,C). After placement of a Frater stitch, the prolapse of the posterior leaflet was evaluated. The posterior leaflet prolapse was corrected by means a technique of plication and suspension of the free edge along a 2-mm-wide strip of polytetrafluoroethylene* (PTFE) applied from one commissure to the other by using 2 running sutures of a 6-0 monofilament passed up and down through the free edge of the leaflet and the PTFE strip (Figure 1,D). The beginning and end of this suture were at each corresponding commissural level in an extra-aortic

*Gore-Tex strip; registered trade name of W. L. Gore \& Associates, Inc, Flagstaff, Ariz. 